\title{
Integrity Evaluation of Micro-/Nanobubble Pump Impeller using Fluid-Structure Coupled Simulation
}

\author{
Hilman Syaeful Alam ${ }^{\#, 1}$ and Bahrudin ${ }^{\#, 2}$ \\ \# Technical Implementation Unit for Instrumentation Development, Indonesian Institute of Sciences, \\ Jl. Sangkuriang Komplek LIPI Gedung 30 Bandung, 40135, Indonesia. \\ ${ }^{1}$ hilm003@lipi.go.id \\ 2bahr003@lipi.go.id
}

\begin{abstract}
Micro-/nanobubble pump needs a high fluid pressure to generate the extra fine bubbles. The most effective method to increase the pressure is to increase the ratio of the number of vane impeller to pump volume. However, it can reduce the dimension of the vane which can degrade the integrity of the structural vanes due to loading. In this paper, the fluid-structure coupled simulation was used to evaluate the structural integrity of the impellerwith three loading conditions. The loads were acentrifugal force, hydraulic pressure, and the combination loads.The hydraulic pressure was imported from the flow calculation using gas-liquid two-phase flow simulation and the centrifugal force was applied to model due to a high rotational speed of the impeller.Based on the simulation results, the maximum stress due to the combination of centrifugal force and hydraulic pressure was8.205 MPaand it was secure with enough strength because it was less than the allowable design stress of $280 \mathrm{MPa}$. Furthermore, the maximum axial and radial deformation of the impeller were $0.0001 \mathrm{~mm}$ and $0.0027 \mathrm{~mm}$ respectively.However, they didn'taffect thenormal working of themicro-/nanobubble pump and the stiffness of impeller also met the requirements. The evaluation method and simulation results from this work can be used as a basic model for the further analysis and improvement of themicro-/nanobubble pump impeller.
\end{abstract}

Keyword- micro-/nanobubble, computational fluid dynamics, fluid-structure interaction, centrifugal force, hydraulic pressure.

\section{INTRODUCTION}

Microbubbles (MBs) and nanobubbles (NBs) are tiny bubbles with a respective diameter of 10-50 $\mu \mathrm{m}$ and $<200 \mathrm{~nm}$ [1]. In recent years, MBs and NBs generation technologies have been the subject of intensive research due to their wide applications in various field and industriessuch as: mineral processing [2], plastic recycling [3], oil-in-water emulsion separation [4], cleaning of hydrophobic material [5], nanomedicines [6], improving engine performances [7], aeration of gas reservoir drilling operation [8], polishing slurry [9] and so on. Gas-liquid mixing pump is one type of microbubble generator that was designed based on hydrodynamic principles, which is very efficient for mixing gas and liquid directly and dissolve them. In general, this type of microbubble generator uses regenerative turbine pump. The regenerative pump is one type of turbomachine that has very simple and inexpensive construction. It achieves lower mass fluxes but higher-pressure differences than other pumps at the same circumferential velocity [10]. The conventional regenerative pump has a construction in which the fluid enters a set of radial impeller teeth which guides the fluid from the inlet to the outlet, both separated by a $300^{\circ}$ annulus chamber producing a toroidal motion also known as regenerative flow [11]. For gas-liquid mixing pump application, a regenerative pump is designed to have two suction for gas and liquid which is mixed within the impeller at high pressures and high rotation to produce MBs and NBs.

The most effective method to increase the pressure on theregenerative pump is to increase the ratio of the number of vane impeller to pump volume [12], however, it can reduce the dimension of the vane which can degrade the integrity of the structure due to loading. The fundamental force of the mixing pump is which driven by theelectrical motor is the fluid mechanical pressure loading on the impeller vanes. The thinner vanes can result in larger deflections due to the lower stiffness of the thinner structure. These deflections change the hydraulic shape of the impeller vane and thus the performance of the pump [13]. In addition, if it exceeds the proportional limit of the material, it will cause a plastic deformation or a permanent damage to the vane component. In order to improve theperformance of mixing pump and to minimize the cost of manufacturing, the mechanical design then becomes challenging to analyze the effects of higher stress levels to the structural integrity of the impeller vanes.

With the rapid development of the computing technology, some numerical simulations were recently performed on multiphase flow problem based on computational fluid dynamic (CFD) simulation for multiphase pump applications. Wang et. al. [14] presented CFD simulation of themultiphase pump to transport gas-liquid two-phase mixtures for improving safety and reliability in thepetroleum industry. Huang et al. [15] also 
presented CFD simulation of gas-liquid two-phase flow in theself-priming process of acentrifugal pump. For assessing the integrity of the solid structure due to fluid pressure loading, the simulation of fluid-structure interaction (FSI) can be performed as many published literatures exist for many application, i.e. pipeline [16], wind turbine vanes [17], pressurized water reactors [18], pressurized tank car [19] and so on. In this paper, thefluid-structure simulation was employed using CFD multiphase flow and structural simulation to study the integrity of liquid-gas mixing pump impeller as a reference in the design process.

\section{Materials AND Methods}

The micro-/nanobubble pump has two suctions or inlet fluids, i.e. gas and liquid which is mixed with the impeller component. Pressure on each impeller vane will continue to increase in line with every level of vane rotation. Pumping works are generated by kinetic energy, centrifugal force, and tangential force.The combination of the three will generatea vortex flow pattern or fluid strands that impact on regenerative effects or impulses that recur the fluid particles at every level of vanesand volute pump channels [10].Gas fine bubbles would be obtained at the outlet of the impellerdue to the super-saturated condition between gas and fluid.The design parameter of the micro-/nanobubble pump was amass flow of $3 \mathrm{~m}^{3} / \mathrm{h}$, head of $20 \mathrm{~m}$, rotation speed of $3000 \mathrm{r} / \mathrm{min}$, and power of $1.2 \mathrm{~kW}$.

\section{A. Mathematical model for Fluid-Structure Interaction}

According to Liu et al. [20], the conservation equations of fluid flow consist of mass conservation, momentum conservation, and energy conservation. However, a centrifuge fluid flow that is generated in gasliquid mixing pump does not consider the energy transfer. Therefore, it can be represented by mass and energy conservation equation as follow:

Mass conservation equation:

$$
\frac{\partial \rho_{f}}{\partial t}+\nabla \cdot\left(\rho_{f} v\right)=0
$$

Momentum conservation equation:

$$
\frac{\partial \rho_{f} v}{\partial t}+\nabla \cdot\left(\rho_{f} v v-\tau_{f}\right)=f_{f}
$$

where $t$ is the time, $f_{f}$ is the volume force vector, $\rho_{f}$ is the fluid density, $v$ is the fluid speed vector, $\tau_{f}$ is the tensor of shearing force which is expressed as:

$$
\tau_{f}=(-p+\mu \nabla \cdot v) I+2 \mu e
$$

where $p$ is the fluid pressure, $\mu$ is the dynamic viscosity, $e$ is the tensor of speed stress, $e=1 / 2\left(\nabla v+\nabla v^{T}\right)$.

Based on the Newton's second law, the conservation equation of structure can be stated as follow:

$$
\rho_{s} \ddot{d}_{s}=\nabla \cdot \sigma_{s}+f_{s}
$$

where $\rho_{s}$ is the structural density, $\sigma_{s}$ is the Cauchy's stress tensor, $f_{s}$ is the volume force vector, $\ddot{d}_{s}$ is the structural local acceleration vector.

In this case, the fluid-structure coupled simulation is not considered the thermal effect. Therefore, the liquid displacement $\left(d_{f}\right)$ and structure displacement $\left(d_{s}\right)$ are equal. Furthermore, the conservation of liquid stress $\left(t_{f}\right)$ and structure stress $\left(t_{f}\right)$ should be satisfied.

$$
\left\{\begin{aligned}
d_{f} & =d_{s} \\
\tau_{f} \cdot n_{f} & =\tau_{s} \cdot n_{s}
\end{aligned}\right.
$$

where $n_{f}, n_{s}$ are the normal direction of $\tau_{f}, \tau_{s}$.

\section{B. Computational domains and meshing}

3D model of thecomputational domain of gas-liquid mixing pump was built using ANSYS Design Modeler, as shown in Fig. 1 (a). The geometry of flow fieldconsisted of solid and fluid domains which were imported into the ANSYS CFX software to generate meshes as shown in Fig. 1 (b). The 3D tetrahedral element was used to mesh the geometry of flow field both for the solid and fluid domain.Hence, there were totally 1,468,659 cells and 429,568 nodes. The geometry of structure field used the same geometry with the flow field but meshing was carried on ANSYS Static Structural. By using 3D tetrahedral elements, the meshing of structure fieldgenerates totally 5,234 cells and 11,056 nodes, as shown in Fig. 2. 


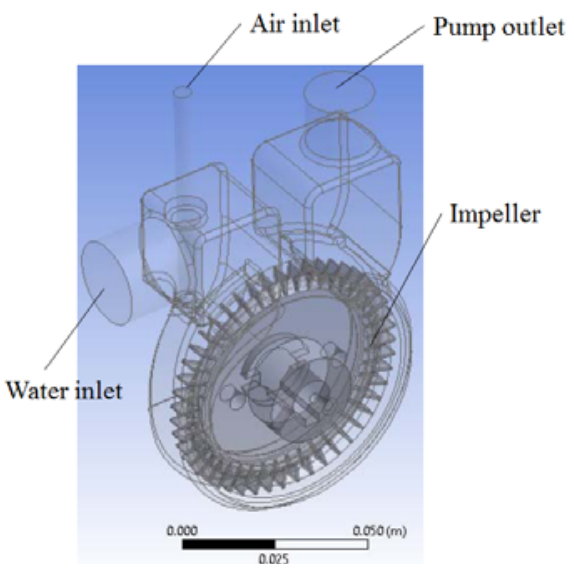

(a)

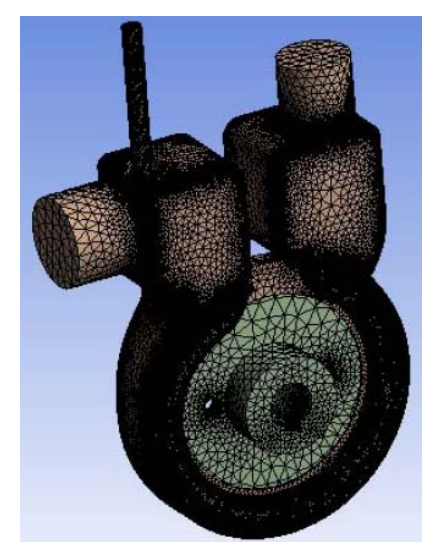

(b)

Fig. 1. (a) 3D computational domain, and (b) mesh generation of computational domain.

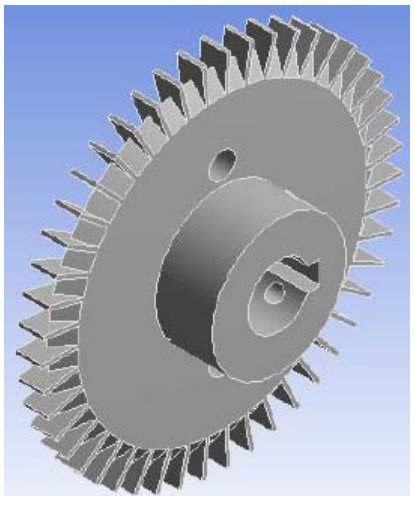

(a)

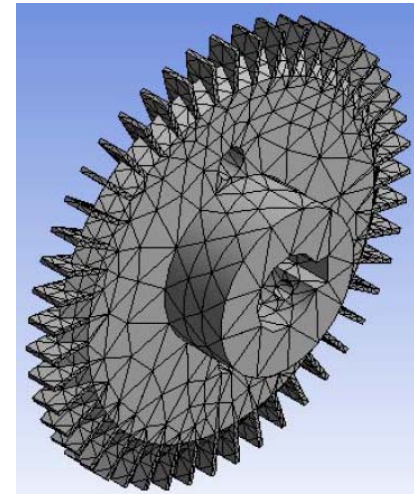

(b)

Fig. 2. (a) Structure geometry, and (b) mesh generation of structure geometry

\section{Boundary conditions}

1) Fluid flow boundary condition: The generation procedures of micro-/nanobubbleswereperformed by running the pump first without air to achieve a negative pressure at the inlet pump between -100 to $-200 \mathrm{mmHg}$. After reaching this condition, the air would be sucked into the pump impeller by self-suction which the initial air pressure in $1 \mathrm{~atm}$. The pressure at the outlet pump outlet was set at $3 \mathrm{~atm}$ in accordance with the design head of $20 \mathrm{~m}$. Therefore, in order to avoid complexity and time-consuming in simulation, fluid flow simulation was directly performed in stable operating conditions that would be obtained the load as an input in fluidstructurecoupled simulation. The fluid flow calculation was based on the gas-liquid two-phase simulation which air and water were set as the working fluid. Water and air at $25 \mathrm{C}$ were set as the continuous fluids. The pumping process was assumed as the isothermal without phase change. The two-phase flow and the standard $\mathrm{k}-$ e turbulence model were selected in the governing equations. The discrete scheme of the two-phase flow, the turbulence kinetic energy, and the turbulent dissipation rate was set to the second order upwind scheme.

2) Boundary conditions of structure field:

According to Liu et al. [20], there are several loading may occur in thehydro-rotating machine,i.e.the centrifugal force generated by high-speed rotation, Coriolis force, and hydraulic pressure. The centrifugal force applied in the form of angular velocity. The angular velocity is a function of rotational speed of $314 \mathrm{rad} / \mathrm{s}$. In this paper, the rotating speed of the impeller is $3000 \mathrm{r} / \mathrm{min}$. In therotary motion, the Coriolis force may arise. However, it is usuallyneglected in engineering problems, because of its weak influence and relatively complex mathematical operation[20]. The hydraulic pressure was imported from the two-phase flow calculation to the structure domain.Therefore, there were two major loads applied on the impeller, i.e. the centrifugal force due to the rotating velocity of theimpeller and the hydraulic pressure whichwas obtained by the two-phase flow calculation.

\section{III.RESULTS AND DISCUSSIONS}

In order to evaluate the structural integrity of micro-/nanobubble pump impeller due to centrifugal force and hydraulic pressure, the model was simulated at three loading conditions to get the stress and deformation of theimpeller.The loads were acentrifugal force, hydraulic pressure, and the combination loads. The centrifugal 
force due to the angular velocity of theimpeller was applied to the model. The hydraulic pressure was imported from the flow calculation, as shown in Fig. 3. Based on Fig. 3, the maximum hydraulic pressure applied on the fluid-structure interface was equal to $0.2681 \mathrm{MPa}$, which was located on the impeller closest to the pump outlet. Therefore, the results that are shown on the fluid flow calculation run normally. The pressure at every level of the impeller vane would continue to increase and the maximum pressure was located near the area of pump outlet. It was appropriate tothe characteristics of the regenerative pump.

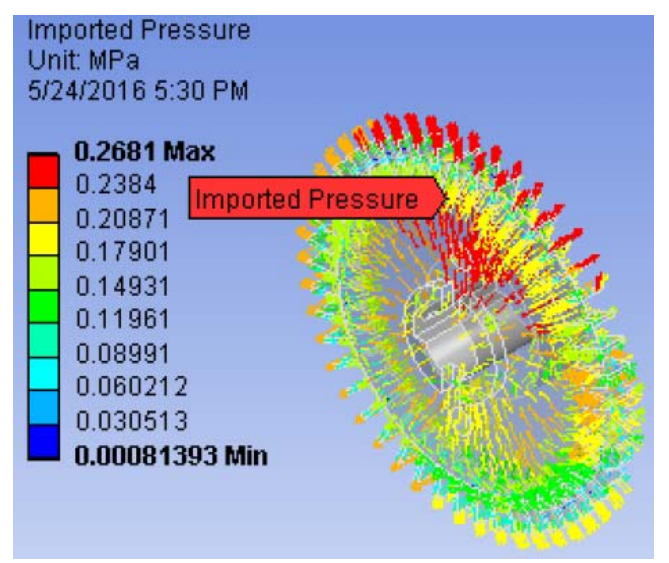

Fig. 3. The imported pressure from the fluid flows calculation.

Based on the static structural analysis, the equivalent stressesof each load are shown inFig. 4. The maximum equivalent stressunder the action of centrifugal force was $0.175 \mathrm{MPa}$ which occurred at the hole of disassembly facility. The maximum equivalent stress under the action of hydraulic pressure was $8.195 \mathrm{MPa}$ which occurred at the impeller vanes closed to the outlet pump. The maximum equivalent stressunder the action of combination loads was 8.205 MPa. The material of impeller was made from Al-alloy with the allowable design stress of 280 $\mathrm{MPa}$.Therefore, the maximum stress of micro-/nanobubble pump impeller was less than the allowable design stress, and it was secure with enough strength.

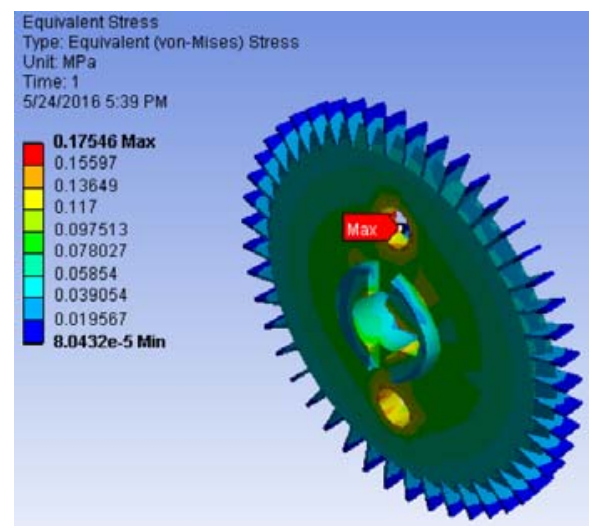

(a)

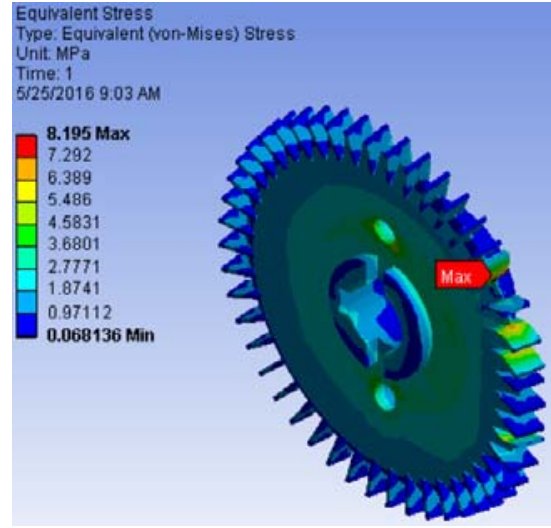

(b)

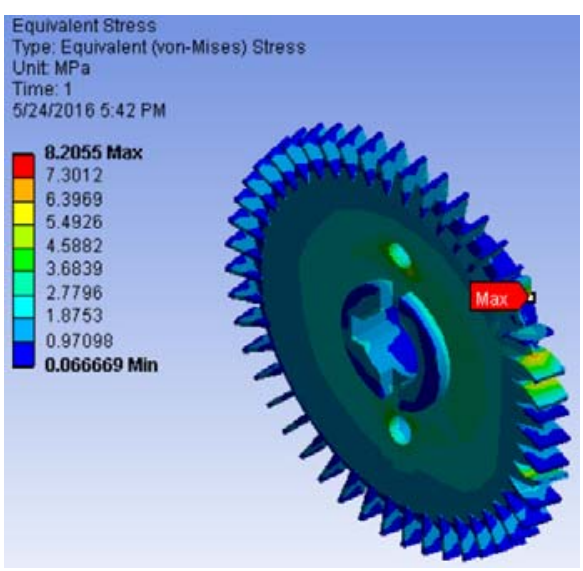

(c)

Fig. 4 The equivalent stress distribution under: (a) centrifugal force, (b) hydraulic pressure, and (c) combination loads. 
The deformation of each load is shown in Fig. 5. The maximum deformation under the action of centrifugal force was $2.754 \mathrm{e}-5 \mathrm{~mm}$. The maximum deformation under the action of hydraulic pressure was $0.005 \mathrm{~mm}$. The maximum deformation under the combination loads was $0.005 \mathrm{~mm}$. The all three maximum deformations occurred at the impeller vanes which closed to the pump outlet.In this study, the results were appropriate with the characteristic of regenerative pumps in Ref. [10] and [11]. The maximum deformation under the centrifugal force was not very significantbecause the deflection effects of the pump shaft were neglected. The deformation under the combination loads did not vary much with the deformation under the hydraulic pressure and the results were not significant.Therefore, the total deformation was certainly not altered the hydraulic shape of the impeller vanes and the performance of the pump.

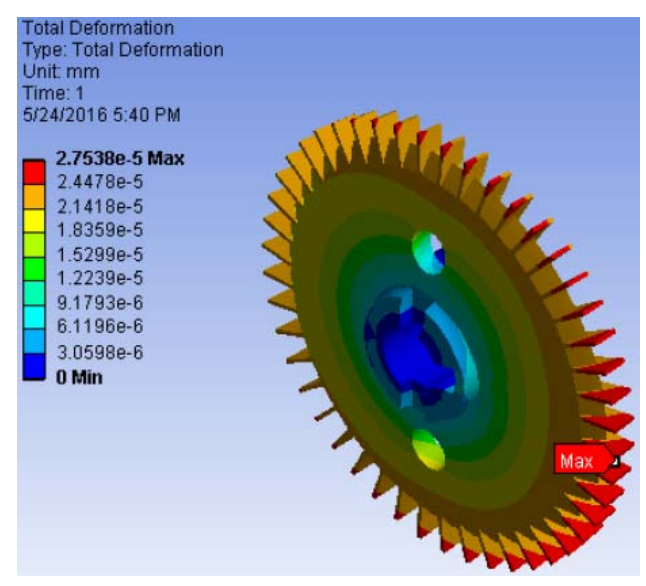

(a)

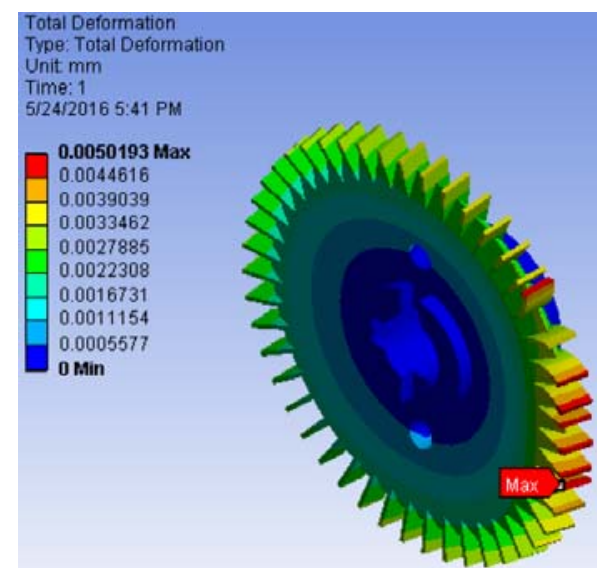

(b)

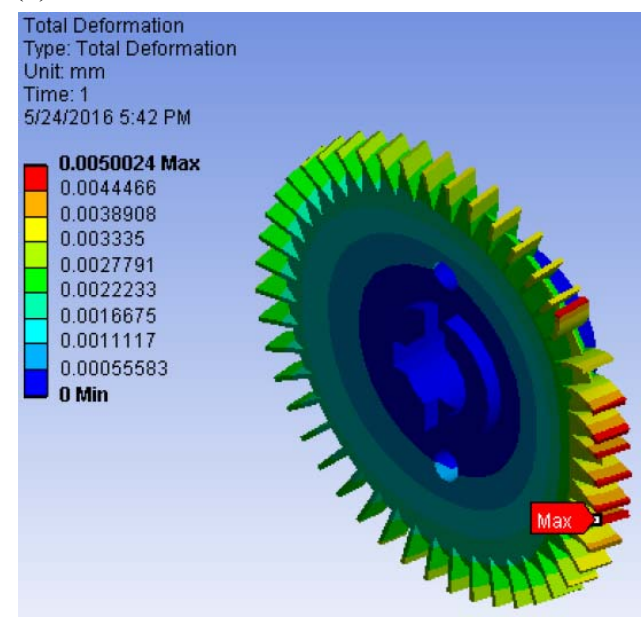

(c)

Fig. 5. Deformation distribution under: (a) centrifugal force, (b) hydraulic pressure, and (c) combination loads.

The axial and radial of total deformation needs to be analyzed to show the extent of deformation can affect the change of the gap between the impeller and volute pump.The axial and radial of total deformation can be seen inFig. 6. The maximum of axial deformation due to combination loads was $0.0001 \mathrm{~mm}$ which was located to be around the connection between the impeller and main shaft. It was much less than $1.0 \mathrm{~mm}$ which is the smallest axial gap between the impeller and the volute pump. Furthermore, the maximum of radial deformation due to combination loads was $0.0027 \mathrm{~mm}$ located in the impeller near the pump outlet. It was much less than $1.5 \mathrm{~mm}$ which is the smallest radial gap between the impeller and volute pump. Therefore, the maximum axial and radial deformation of the impeller was so minimal that cannot have an effect on thenormal working of themicro/nanobubble pump and the stiffness of impeller also met the requirements. 




(a)

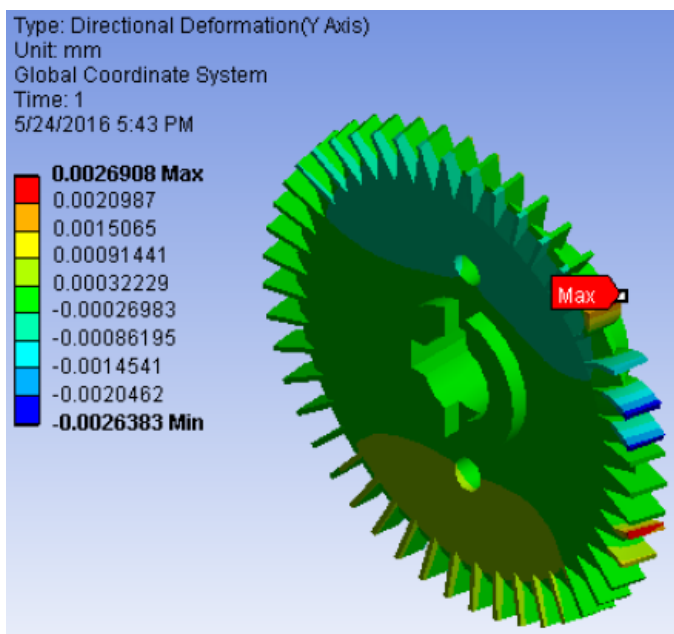

(b)

Fig. 6. The axial and radial deformation under the combination loads.

\section{IV.CONCLUSION}

The structural integrity of the micro-/nanobubble pump impeller was analyzed using ANSYS platform based on the fluid-structure coupling simulation. The following conclusion can be drawn based on the simulation results:

- The maximum stress due to centrifugal force was $0.175 \mathrm{MPa}$ and the maximum stress due to hydraulic pressure was $8.195 \mathrm{MPa}$. It showed that the centrifugal force due to rotational speed had aless significant effect than the hydraulic pressure on the structural strength of the impeller.

- The maximum stress due to combination loads was secure with enough strength because it was less than the allowable design stress. The maximum stress occurred at the impeller vanes close to the pump outlet, which indicates that the simulation results were appropriate with the characteristics of the regenerative pump in the previous reference.

- The maximum total deformation due to combination loads was $0.005 \mathrm{~mm}$, which $0.0001 \mathrm{~mm}$ for axial deformation and $0.0027 \mathrm{~mm}$ for radial deformation. It was much less than $1.0 \mathrm{~mm}$ and $1.5 \mathrm{~mm}$ which is the smallest gap between the impeller and the volute pump for the axial and radial gap respectively.

- The maximum axial and radial deformation of the impeller were so minimal that it cannot have an effect on thenormal working of themicro-/nanobubble pump and the stiffness of impeller also met the requirements.

- The evaluation method and simulation results from this work can be used as a basic modelfor the further analysis and improvement of themicro-/nanobubble pump impeller.

\section{ACKNOWLEDGMENT}

This work was financed by KegiatanUnggulan LIPI, Indonesian Institute of Sciences under Grant 1139/F/2015-03-06. The computational facilities were extended by the Research Center of Electrical Power and Mechatronics, Indonesian Institute of Sciences, which is thankfully acknowledged.

\section{REFERENCES}

[1] A. Agarwal, W. J. Ng, and Y. Liu, "Principle and applications of microbubble and nanobubble technology for water treatment," Chemosphere, vol. 84, no. 9, pp. 1175-1180, 2011.

[2] R. Ahmadi, D. A. Khodadadi, M. Abdollahy, and M. Fan, "Nano-microbubble flotation of fine and ultrafine chalcopyrite particles," Int. J. Min. Sci. Technol., vol. 24, no. 4, pp. 559-566, 2014.

[3] P. Basařová, T. Váchová, G. Moore, G. Nannetti, and J. Pišlová, "Bubble adhesion onto the hydrophobic surface in solutions of nonionic surface-active agents," Colloids Surfaces A Physicochem. Eng. Asp., 2015.

[4] X. Li, H. Xu, J. Liu, J. Zhang, J. Li, and Z. Gui, "Cyclonic state micro-bubble flotation column in oil-in-water emulsion separation," Sep. Purif. Technol., 2016.

[5] K. Matsuura, S. Ogawa, S. Kasaki, K. Koyama, M. Kodama, and S. Yanase, "Cleaning polymer ink from a glass substrate using microbubbles generated by a hydrogen bubble method,” Sep. Purif. Technol., vol. 142, pp. 242-250, 2015.

[6] T. Yin, P. Wang, J. Li, Y. Wang, B. Zheng, R. Zheng, D. Cheng, and X. Shuai, "Tumor-penetrating codelivery of siRNA and paclitaxel with ultrasound-responsive nanobubbles hetero-assembled from polymeric micelles and liposomes," Biomaterials, vol. 35, no. 22, pp. 5932-5943, 2014.

[7] S. H. Oh, S. H. Yoon, H. Song, J. G. Han, and J. M. Kim, "Effect of hydrogen nanobubble addition on combustion characteristics of gasoline engine," Int. J. Hydrogen Energy, vol. 38, no. 34, pp. 14849-14853, 2013.

[8] A. Alizadeh and E. Khamehchi, "Modeling of micro-bubble surfactant multi-layer drilling fluid stability based on single bubble behavior under pressure and temperature in a deviated gas well," J. Nat. Gas Sci. Eng., vol. 26, pp. 42-50, 2015.

[9] H. Aida, S. W. Kim, K. Ikejiri, T. Doi, T. Yamazaki, K. Seshimo, K. Koyama, H. Takeda, and N. Aota, "Precise mechanical polishing of brittle materials with free diamond abrasives dispersed in micro-nano-bubble water," Precis. Eng., vol. 40, pp. 81-86, 2015. 
[10] T. A. Meakhail, "Numerical Study Of Unsteady Flow Characteristics In Regenerative Pump,” vol. 35, no. 4, pp. 933-943, 2007.

[11] K. V. A. K. Aranth and N. Y. A. S. Harma, "CFD Analysis of a Regenerative Pump for Performance Enhancement," no. September, pp. 3-8, 2014.

[12] S. M. Rajmane and S. P. Kallurkar, “CFD Analysis of Domestic Centrifugal Pump for Performance Enhancement,” pp. 984-988, 2015.

[13] H. Schmucker, F. Flemming, S. Coulson, V. H. Gmbh, and C. Kg, "Two-Way Coupled Fluid Structure Interaction Simulation of a Propeller Turbine," vol. 3, no. 4, pp. 342-351, 2010.

[14] J. Wang, H. Zha, J. M. McDonough, and D. Zhang, "Analysis and numerical simulation of a novel gas-liquid multiphase scroll pump," Int. J. Heat Mass Transf., vol. 91, pp. 27-36, 2015.

[15] S. Huang, X. Su, J. Guo, and L. Yue, "Unsteady numerical simulation for gas-liquid two-phase flow in self-priming process of centrifugal pump,” Energy Convers. Manag., vol. 85, pp. 694-700, 2014.

[16] Y. S. Chang, S. H. Kim, H. S. Chang, S. M. Lee, J. B. Choi, Y. J. Kim, and Y. H. Choi, "Fluid effects on structural integrity of pipes with an orifice and elbows with a wall-thinned part,” J. Loss Prev. Process Ind., vol. 22, no. 6, pp. 854-859, 2009.

[17] A. Simulia and T. Brief, "Abaqus Technology Brief Fully Coupled Fluid-Structure Interaction Analysis of Wind Turbine Rotor Blades," no. April, pp. 1-4, 2012.

[18] G. Ricciardi, "Fluid - structure interaction modelling of a PWR fuel assembly subjected to axial flow," J. Fluids Struct., vol. 62, pp. $156-171,2016$.

[19] H. Yu and D. Y. Jeong, "Impact dynamics and puncture failure of pressurized tank cars with fluid-structure interaction: A multiphase modeling approach,” Int. J. Impact Eng., vol. 90, pp. 12-25, 2016.

[20] H. Liu, P. Li, H. Xiao, and W. Mu, "The fluid-solid coupling analysis of screw conveyor in drilling fluid centrifuge based on ANSYS," Petroleum, vol. 1, no. 3, pp. 251-256, 2015.

\section{AUTHOR PROFILE}



Hilman Syaeful Alam received his Bachelor degree in mechanical engineering from JenderalAchmadYani University, Indonesia in 2003 and Master degree in Mechanical Engineering from InstitutTeknologi Bandung, Indonesia in 2010, He worked as a researcher at Indonesian Institute of Sciences (LIPI) from 2006 until now. His research areas are mechanical engineering, engineering design, instrumentation \& control, and computational mechanics.

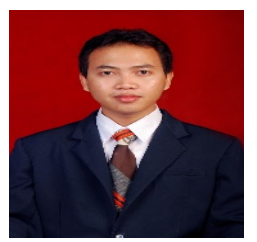

Bahrudin received is Bachelor degree in mechanical engineering from Brawijaya University, Indonesia in 2012. He worked as a researcher candidate at Indonesian Institute of Sciences (LIPI) from 2014 until now. His research areas are renewable energy, optimization, fluid mechanic, finite element, and instrumentation \& control. 